\title{
Comparison of Fabrication Methods of Metal-Organic Framework Optical Thin Films
}

\author{
Yan Huang ${ }^{1, \dagger}$, Cheng-an Tao ${ }^{2, *,+}\left(\mathbb{D}\right.$, Rui Chen ${ }^{2}$, Liping Sheng ${ }^{1, *}$ and Jianfang Wang ${ }^{2, *}$ \\ 1 National \& Local Joint Engineering Laboratory for New Petro-chemical Materials and Fine Utilization \\ of Resources, College of Chemistry and Chemical Engineering, Hunan Normal University, \\ Changsha 410081, China; 15211097117@163.com \\ 2 College of Liberal Arts and Science, National University of Defense Technology, Changsha 410073, China; \\ chenrui95@live.com \\ * Correspondence: tca02@mails.thu.edu.cn (C.-a.T.); sleeping1217@126.com (L.S.); \\ wangjianfang@nudt.edu.cn (J.W.); Tel.: +86-731-8457-4241 (J.W.) \\ + These authors contributed equally to this work.
}

Received: 6 August 2018; Accepted: 28 August 2018; Published: 30 August 2018

\begin{abstract}
Homogeneous metal-organic frameworks (MOFs)-based optical thin films have attracted increasing attention, since they can potentially be used as active components in optical/opt-electrical devices, and how to fabricate MOF thin films with high quality is the premise of practically using them. Herein, five fabrication methods of MOF films are systematically investigated and compared from the aspects of appearance, reflectivity, micro-morphology, surface roughness, and optical properties of the films. The famous robust $\mathrm{Zr}$-based MOF, $\mathrm{UiO}-66(\mathrm{UiO}=$ University of Oslo) is chosen as a model, and the five methods are spin-coating, dip-coating, self-assembly, direct growth, and the stepwise layer by layer growth method. This study provides fundamental support for the application of MOFs in the optical field.
\end{abstract}

Keywords: metal-organic frameworks; thin film; optical property; fabrication method

\section{Introduction}

Metal-organic frameworks (MOFs) are a class of inorganic-organic hybrid crystalline materials that consist of metal ions or clusters and organic bridging ligands via coordinate-covalent bonds [1,2]. They have exhibited great potential for applications in many fields, such as gas storage [3], catalysis [4,5], drug delivery [6], chemical sensing [7-10], and so on, benefitting from their outstanding features, including ultrahigh porosity, large internal surface area, good thermal stability, and high chemical tailorability [11-13].

Optical thin films (OTFs) are composed of single or multi-layered media with uniform thicknesses [14]. They form the basis of developing a variety of optical elements and devices, such as anti-reflection coatings, high reflectivity films, polarizing films, long/short-pass filters, and beam splitters [15]. The countless types, the tunable optical properties, and the above-mentioned unique characteristics of MOFs make them a promising new generation of optical thin film materials. But, how to fabricate MOF optical thin films with high quality (low roughness) is a chief and fundamental issue. Recently, homogeneous MOF-based thin films [16,17], particularly optical thin films [18-23], have attracted more and more attention, since they can potentially be used as active components (which can be easily regulated) in functional devices [16,17]. To date, several strategies have been developed for preparing MOF thin films. Férey and coworkers [18] first prepared flexible porous iron(III) trans, trans-muconate MIL-89 (MIL = Materials of Institut Lavoisier) colloidal optical thin films using the dip-coating method, and expanded on chromium terephthalate MIL-101(Cr) [19], 
chromium trimesate MIL-100(Cr) [20], and iron(III) trimesate MIL-100(Fe) [20]. Lotsch's group [24] fabricated MOF thin films by spin-coating a MOF nanoparticle suspension onto a flat substrate. Two kinds of MOFs have been explored. One is copper trimesate $\left(\mathrm{Cu}_{3}(\mathrm{BTC})_{2}\right.$, also known as HKUST-1, HKUST = Hong Kong University of Science \& Technology), which contains Cu(II)-paddlewheel-type nodes and trimesate struts, and the other one is the isoreticular metal-organic framework-3 (IRMOF-3, zinc amino-terephthalate). Our group $[10,22,23,25]$ successfully applied this method to construct many MOF thin films, such as iron(III) terephthalate MIL-88B, aluminium terephthalate MIL-53, MIL-101(Cr), and their analogues. Huo et al. [9] developed a self-assembly method by dispersing zirconium(IV) terephthalate metal organic framework $\mathrm{UiO}-66(\mathrm{UiO}=$ University of Oslo) nanoparticles on the surface of water and transferring the self-assembled MOF thin film to a substrate. Lu et al. [8] constructed zeolitic imidazolate framework (ZIF)-8-based optical thin films via a direct growth method that functioned as selective sensors for chemical vapors and gases. Redel et al. [21] presented the optical properties of HKUST-1 thin film (also called surface-anchored metal-organic frameworks, SurMOF) which were fabricated by stepwise layer by layer growth onto a substrate. Although there have been a few successful cases to prepare MOF thin films, there is still a lack of systematic exploration on the performance and potential application of the thin films from the perspective of optical films. Moreover, for the same MOF system, there is a lack of detailed comparison on these preparation methods. In addition, the stability of optical thin films is vital for practical application. Generally, the MOFs have poor water stability, which hinders $\mathrm{MOF}$ thin film use in actual devices. A famous robust Zr-based MOF, UiO-66, based on terephthalate linkers and 12-coordinate cationic $\mathrm{Zr}_{6} \mathrm{O}_{4}(\mathrm{OH})_{4}{ }^{12+}$ clusters (Scheme 1a) is optically transparent in the visible region and has exceptional mechanical, chemical, and thermal stabilities $[13,26]$, especially aqueous stability over a range of $\mathrm{pH}$ values. If UiO-66 can be successfully prepared into a high quality optical film, it will be possible to apply it to actual optical or optoelectronic devices in the future.

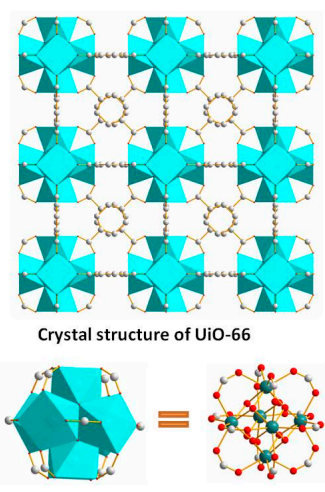

Zr-O metal centers

(a)

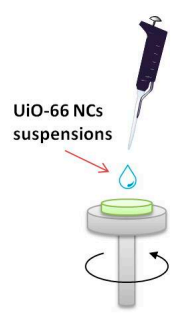

(b)

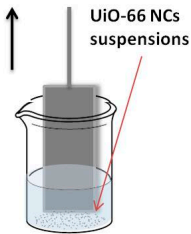

(c)

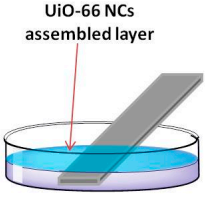

(d)

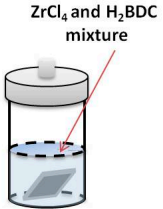

(e)

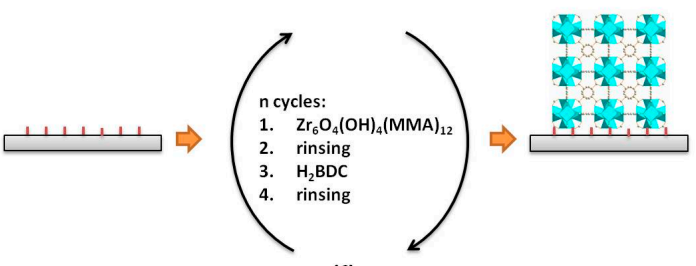

(f)

Scheme 1. (a) Crystal structure of UiO-66, consisting of $\mathrm{Zr}-\mathrm{O}$ metal centers connected by terephthalate linkers. Zr, cyan; C, gray; $\mathrm{O}$, red; $\mathrm{H}$, omitted. (b-f) Illustration of five fabrication methods of metal-organic framework (MOF) optical thin film: (b) spin-coating, (c) drop-coating, (d) self-assembly, (e) direct growth, (f) stepwise layer by layer growth method.

In this study, UiO-66 was chosen as a model. The UiO-66 thin films were fabricated by five methods (Scheme 1b-f), i.e. spin-coating (SP), dip-coating (DP), self-assembly (SA), direct growth (DG), and the stepwise layer by layer growth (LBL) method, and the according thin films were denoted as OTF-SP, OTF-DP, OTF-SA, OTF-DG, and OTF-LBL, respectively. These optical thin films were compared from the aspects of appearance, reflectivity, micro-morphology, surface roughness, and optical properties. The OTF-SP film has a uniform color, greater reflectivity, flat microstructure, 
and minimal roughness. The quality of OTF-DP and OTF-SA films depends on the deposition times. The OTF-DG film has the highest roughness, which cannot meet the requirement for the use in optical films. The OTF-LBL film has the brightest color, a dense and smooth film surface, low surface roughness, and the maximum effective refractive index. This study provides fundamental support for the application of MOFs in the optical field.

\section{Experimental Section}

\subsection{Materials}

UiO-66 nanocrystals (NCs) were synthesized according to literature [12,27], and characterized by scanning electron microscopy (SEM), Fourier transform infrared (FTIR), X-ray diffraction (XRD), $\mathrm{N}_{2}$ adsorption-desorption isotherm and thermogravimetric analysis (Figure S1). The UiO-66 suspensions were prepared by dispersing the $\mathrm{UiO}-66$ nanocrystals in $\mathrm{EtOH}$. The 12-coordinate cationic $\mathrm{Zr}_{6} \mathrm{O}_{4}(\mathrm{OH})_{4}{ }^{12+}$ clusters based precursor (Zr-precursor) $[28,29]$ was prepared by reaction of methacrylic acid and $\mathrm{Zr}(\mathrm{PrO})_{4}$ and confirmed by XRD and FTIR. (Figures S6 and S7). All reagents were used as received without further purification.

Silicon wafers were cut into small pieces $(\sim 2 \mathrm{~cm} \times 2 \mathrm{~cm})$ which were used as substrates for fabrication of MOF thin films. The substrates were pre-cleaned with soap and water and subsequently treated with piranha solution $\left(\mathrm{H}_{2} \mathrm{SO}_{4} / \mathrm{H}_{2} \mathrm{O}_{2}\right.$, volumetric ratio $\left.7: 3\right)$ at $70{ }^{\circ} \mathrm{C}$ for $1 \mathrm{~h}$. After thorough rinsing with deionized water, the wafers were dried under air flow and stored in ethanol. For spin-coating, dip-coating, self-assembly deposition, and direct growth, the substrates were dried under nitrogen flow before use. For layer-by-layer growth, the substrates were functionalized with $\mathrm{H}_{2} \mathrm{BDC}$ by incubating in a $\mathrm{N}, \mathrm{N}$-dimethyl formamide (DMF) solution containing $33 \mathrm{mM} \mathrm{H}_{2} \mathrm{BDC}$ at room temperature for $3 \mathrm{~h}$, and then cleaned with ethanol and dried with a stream of nitrogen gas before use.

\subsection{Preparation of MOF Optical Thin Film}

The OTF-SP films were fabricated by spin-coating $200 \mu \mathrm{L}$ of UiO-66 nanocrystals alcoholic suspensions ( $4.3 \mathrm{wt}$. \%) onto the substrate at $3000 \mathrm{rpm}$ for $60 \mathrm{sec}$ (Scheme 1b). The OTF-DP films were fabricated by dip-coating UiO-66 nanocrystals alcoholic suspensions (4.3 wt. \%) using a withdrawal speed of one $\mathrm{mm} \cdot \mathrm{s}^{-1}$ (Scheme 1c). The deposition process was performed once, thrice, and five times, and the corresponding thin films were denoted as OTF-DP-1, OTF-DP-3, and OTF-DP-5, respectively. The OTF-SA films were prepared according to a previous report [9], in brief, the polyvinylpyrrolidone (PVP)-functionalized UiO-66 nanocrystals self-assembled on the water-air interface, and then the formed close-packed monolayer of UiO-66 nanocrystals was transferred onto the silicon substrate through the simple dip coating process (Scheme 1d). The process was repeated for one, two, or three times and the corresponding thin films were denoted as OTF-SA-1, OTF-SA-2, and OTF-SA-3, respectively. The OTF-DG films were hydrothermally prepared by putting the silicon substrate in the precursor solution $\left(\mathrm{ZrCl}_{4}\right.$ :terephthalic acid $\left(\mathrm{H}_{2} \mathrm{BDC}\right): \mathrm{H}_{2} \mathrm{O}$ :acetic acid: $\left.\mathrm{DMF}=1: 1: 1: 500: 1500\right)$ (Scheme 1e). The OTF-LBL films were fabricated by dipping the functionalized substrate successively in (1) an ethanolic Zr-precursor (2 mM) solution, (2) absolute ethanol, (3) an ethanolic $\mathrm{H}_{2} \mathrm{BDC}$ (2 mM) solution, and again (4) absolute ethanol for 35 cycles (Scheme 1f). The experimental details were shown in Supplementary Materials.

\subsection{Characterization}

FTIR spectra were obtained using a Spectra Two spectrophotometer (PerkinElmer, Waltham, MA, USA) from $4000 \mathrm{~cm}^{-1}$ to $500 \mathrm{~cm}^{-1}$ with an attenuated total reflection (ATR) accessory. The XRD patterns were collected using a Ttr III type X-ray diffractometer (Rigaku, Tokyo, Japan) in $\theta-\theta$ geometry with a graphite-monochromated $\mathrm{CuK}_{\alpha}$ radiation source. The $\mathrm{N}_{2}$ adsorption-desorption isotherm of the samples at liquid nitrogen temperature $(78 \mathrm{~K})$ and gas saturation vapor tension range was 
measured by a BEL Mini sorption instrument (Bel Japan Inc., Osaka, Japan). TGA was completed by a STA6000 thermogravimetric analyzer (Perkin Elmer, Waltham, MA, USA) at a scanning rate of $10{ }^{\circ} \mathrm{C}$ min $^{-1}$ under $\mathrm{N}_{2}$ atmosphere from 30 to $700{ }^{\circ} \mathrm{C}$. A fiber spectrometer (USB2000+, Ocean optics, El Dorado Hills, CA, USA) coupled to an optical microscope (the numerical aperture of the $100 \mathrm{X}$ microscope objective is 0.80) was used to measure the specular reflectance in the 400-900 nm range at the normal incidence. SEM images were obtained using an S-4800 electron microscope (Hitachi, Ibaraki, Japan). The samples were sputtered with a thin layer of Au prior to imaging. The surface profiles were characterized using a profilometer (Talysurf PGI 1240, Taylor-Hobson, Leicester, UK) with a diamond stylus. Ellipsometry measurements performed with a XLS-100 ellipsometer (Woollam, Lincoln, NE, USA) at an angle of $75^{\circ}$, and within a spectral range of 400-900 $\mathrm{nm}$ at room temperature.

\section{Results and Discussion}

\subsection{Appearance and Reflectivity}

As shown in Scheme 1a, in perfect crystal structure of $\mathrm{UiO}-66$, each $\mathrm{Zr}-\mathrm{O}$ metal center $\left[\mathrm{Zr}_{6} \mathrm{O}_{4}(\mathrm{OH})_{4}\right.$ octahedron] is fully coordinated by 12 terephthalate linkers to form a highly connected framework. The UiO-66 nanocrystals exhibit octahedron morphology, that has a side length of approximately $340 \mathrm{~nm}$ (Figure S1). Compared with FT-IR spectra of $\mathrm{H}_{2} \mathrm{BDC}$ (Figure S2), the bands of protonated carboxylic groups at around 1,710 $\mathrm{cm}^{-1}$ disappear in UiO-66, indicating that the carboxyl groups of ligands have been coordinated with $\mathrm{Zr}-\mathrm{O}$ metal center. The observed powder XRD pattern of UiO-66 (Figure S3) is consistent with the simulated pattern of the UiO-66 single crystal structure, which confirms the formation of pure MOFs. The isotherm of UiO-66 (Figure S4a) shows typical absorption of a microporous material. The calculated Brunauer-Emmett-Teller (BET) surface area of the UiO-66 nanocrystals is $1030.6 \mathrm{~m}^{2} / \mathrm{g}$. Accordingly, the total pore volume was $0.445 \mathrm{~cm}^{3} / \mathrm{g}$. Based on the desorption isotherms, the pore size of $\mathrm{UiO}-66$ was $0.7 \mathrm{~nm}$, as evaluated by the MP method (Figure S4b). UiO-66 nanocrystals also exhibits good thermal stability up to $400{ }^{\circ} \mathrm{C}$ (Figure S5). All these results confirm the success of the preparation of UiO-66 nanocrystals. In general, octahedron-shaped nanoparticles are more difficult to form homogenous and flat films than spherical nanoparticles. In previous reports on chemical solution deposition of MOF nanoparticles, most of the MOF particles used were ball shaped (or quasi-spherical) [10,18-20,22,23], such as MIL-89, MIL-100, MIL-53, MIL-101, HKUST-1, IRMOF-3 etc. Here, octahedral UiO-66 nanocrystal-based thin films were fabricated by spin-coating, dip-coating, and the self-assembly method. Figure 1a shows the optical thin film fabricated by spin-coating, which displays a uniform pink color. The corresponding reflection spectrum is shown in Figure S8, the maximum of reflection of $800 \mathrm{~nm}$ reaches 95\%. All OTF-DP films (OTF-DP-1, OTF-DP-3, and OTF-DP-5) show yellow (Figure 1b-d), but the coverage and surface morphology are different. For OTF-DP-1, the coverage is lowest (about 44\%), which induces some areas of the substrate to be exposed. For OTF-DP-3, the surface is continuous and uniform. For OTF-DP-5, there are many pinholes on the surface, and is a darker yellow color. The reflectance spectra of them are very similar (Figure S9), which agrees with their colors. The OTF-SA shows varied color for different deposition times, from light yellow (once), dark yellow (twice), to yellowish green (trice) (Figure 1e-g). The corresponding reflection spectra have reflection peaks at $574 \mathrm{~nm}, 598 \mathrm{~nm}$, and $567 \mathrm{~nm}$, respectively (Figure S10). Besides, the MOF thin films were also constructed by hydrothermal direct growth, the obtained OTF-DG shows dark green and looks lackluster (Figure 1h), which is in agreement with its reflection spectrum which has no apparent reflections between $400 \mathrm{~nm}$ and $700 \mathrm{~nm}$ (Figure S11). The last method for preparing MOF thin films is stepwise layer-by-layer, and the produced thin film (OFT-LBL) shows vivid blue (Figure 1i), and there is a reflection peak at $450 \mathrm{~nm}$ (Figure S12). The reflection spectrum of OFT-LBL is the smoothest among these thin films. The smooth spectrum means there is less light scattering by the film because of the absent of obvious aggregations or cracks. This result is in agreement with SEM observation, further suggesting the OFT-LBL film is uniform and compact. 

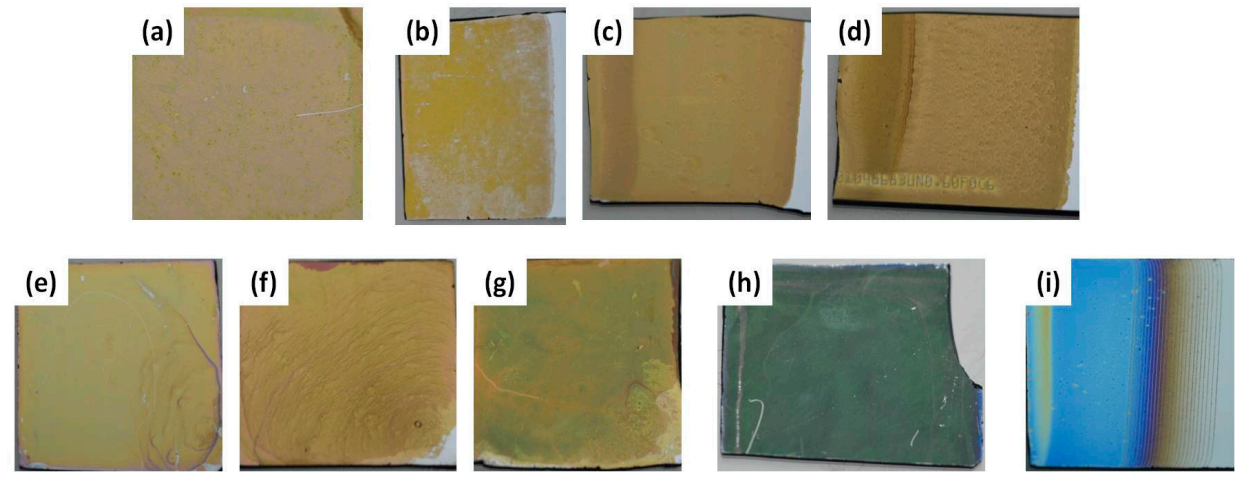

Figure 1. Photographs of MOF optical thin films. (a) OTF-SP, (b) OTF-DP-1, (c) OTF-DP-3, (d) OTF-DP-5, (e) OTF-SA-1, (f) OTF-SA-2, (g) OTF-SA-3, (h) OTF-DG, (i) OTF-LBL.

\subsection{Surface Micro-Morphology}

Surface micro-morphologies of the optical thin films were observed by SEM, as shown in Figure 2. From the top view of SEM images (Figure 2a,g,m), the surface micro-morphologies of OTF-SP, OTF-DP-5, and OTF-SA-3 are almost the same, and UiO-66 nanocrystals gather into small domains with obvious gaps between the domains. When the film is dried, UiO-66 colloidal particles are more likely to attract each other and accumulate due to the capillary force, and induced the cracks between the domains. As a whole, the film is still relatively flat. The flatness (to represent with standard deviation of the thickness of the film measured in the side-view SEM images) of OTF-SP $(14 \mathrm{~nm})$ is better than that of OTF-DP-5 (19 nm), which is better than that of OTF-SA-3 $(21 \mathrm{~nm})$. For the film deposited only once by dip-coating (Figure 2c), the surface coverage is only $44.4 \%$, estimated from the black and white binary SEM images with Image J software [30]. The discrete UiO-66 nanocrystals are distributed across the surface of the substrate. For OTF-DP-3 film (Figure 2e), some areas show the accumulation of UiO-66 nanocrystals. Therefore, under our experimental conditions, more than five depositions are required to obtain a more uniform film. For the self-assembly method, a single-layer film of MOFs can be obtained by the self-assembly once (Figure 2i). When self-assembling twice, the nanocrystals of the second layer are randomly deposited into the gap between the first layer of nanocrystals to improve surface coverage of the film (Figure 2k). From the side view of the SEM image (Figure 2b), the film obtained by the spin coating process is basically composed of two layers of UiO-66 nanocrystals, with a thickness of about $380 \pm 14 \mathrm{~nm}$. The OTF-DP-1 film (Figure 2d) is primarily composed of sparse monolayers of nanocrystals and has a thickness of about $175 \pm 47 \mathrm{~nm}$. The OTF-DP-3 film (Figure 2f) is not uniform, with both monolayer and multi-layer stacking present. The OTF-DP-5 film (Figure 2h) is mostly composed of double-layered nanocrystals with a thickness of about $503 \pm 19 \mathrm{~nm}$. During self-assembly deposition, the number of nanocrystal layers of the film corresponds to the number of assemblies. The OTF-SA-1 is composed of a single layer of nanocrystals and has a thickness of about $252 \pm 25 \mathrm{~nm}$ (Figure 2j). When it is assembled twice, it is mostly composed of interleaved double-layered nanocrystals with a thickness of about $498 \pm 22 \mathrm{~nm}$ (Figure 21). When assembled three times, the resulting film consists of three layers of nanocrystals and the thickness increased to about $606 \pm 21 \mathrm{~nm}$ (Figure 2n). Unlike the solution-based deposition methods of MOF nanoparticles, the film obtained by the direct growth method consists of a single layer of UiO-66 crystals with varied sizes, as shown in Figure 2o. The large grains are about one micron, while the small grains are less than $200 \mathrm{~nm}$. The surface is very rough, and the uneven thickness of the film can also be seen from the side-view SEM image (Figure 2p). The OFT-LBL film obtained after 35 cycles looks very dense (Figure 2q), there are no cracks or pinholes on the surface. Generally, the film is very uniform. From the side view (Figure 2r), it is also seen that the film is dense and identical with a thickness of about $153 \pm 7 \mathrm{~nm}$ and a cycle of about $4.3 \mathrm{~nm}$. From the above results, we can see that the three methods based on the deposition of nanoparticles can obtain relatively flat optical thin films, but the surface 
has cracks; and the film generated by direct growth has a large roughness (40 nm), low coverage $(\sim 50 \%)$, and uneven thickness, making it unable to meet the requirements of optical films; while the layer-by-layer deposited film is smooth, uniform, and has the best coverage and compactness.
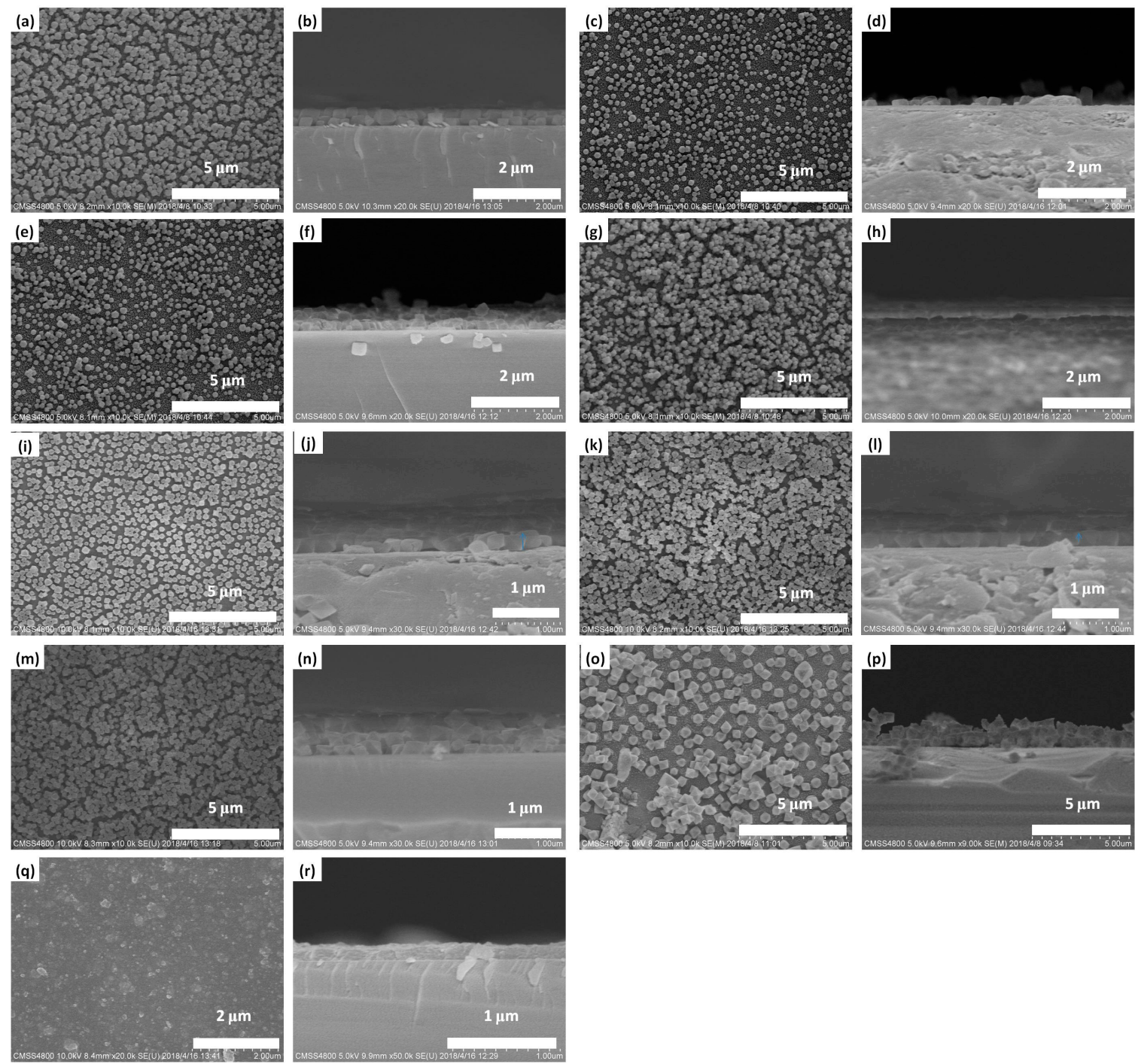

Figure 2. Top-view $(\mathbf{a}, \mathbf{c}, \mathbf{e}, \mathbf{g}, \mathbf{i}, \mathbf{k}, \mathbf{m}, \mathbf{o}, \mathbf{q})$ and side-view $(\mathbf{b}, \mathbf{d}, \mathbf{f}, \mathbf{h}, \mathbf{j}, \mathbf{l}, \mathbf{n}, \mathbf{p}, \mathbf{r})$ SEM images of MOF optical thin films. (a,b) OTF-SP, (c,d) OTF-DP-1, (e,f) OTF-DP-3, (g,h) OTF-DP-5, (i,j) OTF-SA-1, (k,1) OTF-SA-2, $(\mathbf{m}, \mathbf{n})$ OTF-SA-3, (o,p) OTF-DG, $(\mathbf{q}, \mathbf{r})$ OTF-LBL.

\subsection{Surface Roughness}

Furthermore, the qualities of the films were quantitatively analyzed using surface roughness. The surface roughness was determined using a profilometer with a diamond stylus. The sampling length and evaluating length were $0.08 \mathrm{~mm}$ and $2 \mathrm{~mm}$, respectively. The total evaluating length was $10 \mathrm{~mm}$ for evaluating five times. The roughness profiles of UiO-66-based thin films are shown in Figures S13-S21. The arithmetic average roughness, $R_{\mathrm{a}}$ is the arithmetic average value of filtered roughness profile and the root mean squared roughness, $R_{\mathrm{q}}$ is root mean squared value of filtered roughness profile. The calculated $R_{\mathrm{a}}$ and $R_{\mathrm{q}}$ are listed in Table 1. The OTF-SP film has the best flatness, while the OTF-DG has the worst roughness $\left(R_{\mathrm{a}}=40.3 \mathrm{~nm}\right)$. The roughness of MOF thin films made of octahedral UiO-66 nanocrystals is generally higher than that of spherical MOF nanoparticles-based thin films $[19,22,23]$. For the dip-coated films, the more depositions, the larger the roughness due to the 
accumulation, which is consistent with the SEM observation. For the self-assembled films, the trend is just the opposite. Their roughness decreases with the increase of depositions, thanks to the interleaved filling of following nanocrystals, which is in agreement with the micro-morphology.

Table 1. Roughness of MOF optical thin films.

\begin{tabular}{ccc}
\hline Samples & $\boldsymbol{R}_{\mathbf{a}}(\mathbf{n m})$ & $\boldsymbol{R}_{\mathbf{q}}(\mathbf{n m})$ \\
\hline OTF-SP & $8.7 \pm 1.3$ & $12.1 \pm 1.9$ \\
OTF-DP-1 & $7.6 \pm 0.7$ & $9.7 \pm 1.0$ \\
OTF-DP-3 & $13.8 \pm 5.1$ & $17.7 \pm 6.4$ \\
OTF-DP-5 & $25.5 \pm 4.8$ & $42.2 \pm 16.8$ \\
OTF-SA-1 & $15.6 \pm 2.0$ & $19.5 \pm 2.3$ \\
OTF-SA-2 & $15.2 \pm 1.9$ & $21.5 \pm 0.7$ \\
OTF-SA-3 & $10.9 \pm 2.5$ & $19.2 \pm 9.8$ \\
OTF-DG & $40.3 \pm 6.2$ & $56.3 \pm 9.6$ \\
OTF-LBL & $14.2 \pm 1.4$ & $19.3 \pm 7.9$ \\
\hline
\end{tabular}

\subsection{Optical Properties}

The optical constants of the MOFs-based thin films were explored by spectroscopic ellipsometry. The ellipsometric parameters (Psi, Delta) were obtained in the wavelength range of 400-900 $\mathrm{nm}$ at an incident angle of $75^{\circ}$. A Cauchy model was chosen to fit the experimental data. The experimental and generated ellipsometric parameters of the films are presented in Figures S22-S26. The fitting of all MOF thin films present sufficient agreement with the experimental data over the entire measured spectral range, except the film produced by direct growth (Figure S26), suggesting that OTF-DG films cannot meet the requirement of the optical films due to their high roughness. The corresponding thicknesses evaluated via ellipsometry were $379 \pm 5 \mathrm{~nm}$ (OTF-SP), $285 \pm 9 \mathrm{~nm}$ (OTF-DP-1), $462 \pm 7 \mathrm{~nm}$ (OTF-DP-3), $813 \pm 4$ nm (OTF-DP-5), $273 \pm 1$ nm (OTF-SA-1), $545 \pm 5 \mathrm{~nm}$ (OTF-SA-2), $829 \pm 6 \mathrm{~nm}$ (OTF-SA-3), and $153 \pm 2 \mathrm{~nm}$ (OTF-LBL), respectively. The variation tendency of the thickness agrees well with the SEM observation. The roughness of the thin films led the ellipsometry method to overestimate their thicknesses because of the high domain on the surface of thin film would be recognized as the surface level. Interestingly, benefiting from the dense and smooth surface of the OTF-LBL film, the thicknesses of OTF-LBL film estimated from SEM observation and ellipsometry method are almost equal. The obtained optical constants for the MOF thin film as a function of wavelength are shown in Figure 3 and Figure S27. In general, the refractive index $(n)$ of the films has this order: OTF-DP < OTF-DP < OTF-SA < OTF-LBL. The $n$ of OTF-LBL has the highest value, which can be considered as the intrinsic refractive index of UiO-66 due to the compactness and integrity of the film. For convenience of discussion, the average index values (from $400 \mathrm{~nm}$ to $900 \mathrm{~nm}$ ) and that at the wavelength of $900 \mathrm{~nm}$ (the longest wavelength in the measured range) for all samples are listed in Table 2. The nanocrystal-based films can achieve a refractive index lower than 1.23, which is important for application as antireflection film. Such low refractive index benefits from the cracks and voids between the UiO-66 nanocrystals. Assuming the intrinsic refractive index of UiO-66 was 1.5120 , the index of air is 1 , the void percent in the film was estimated according to the effective medium theory $[13,23,31]$. The results are shown in Table 2 . We can see that the voids of OTF-SP, OTF-DP, and OTF-SA films are about $25 \%, 30 \%$, and $23 \%$ respectively. 


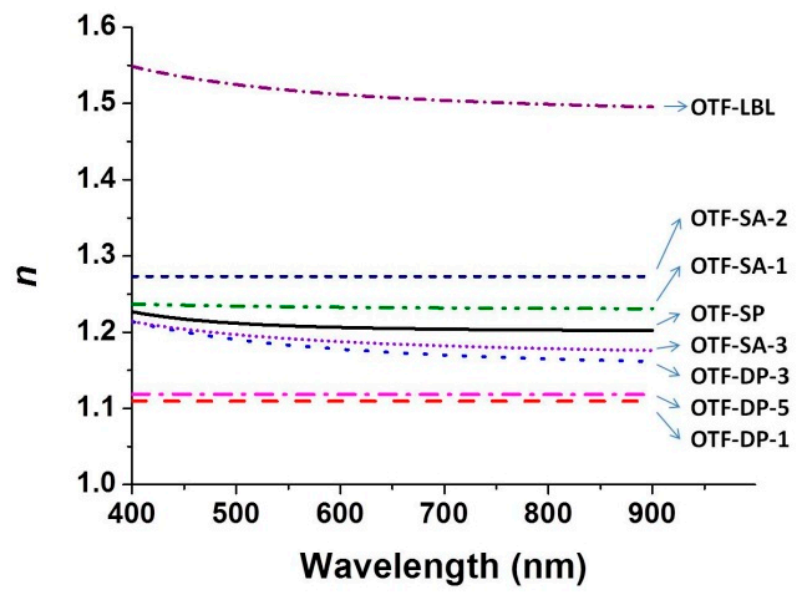

Figure 3. Efficient refractive index of MOF optical thin films.

Table 2. Average efficient refractive index $\left(n_{\text {ave }}\right)$, specific efficient refractive index at $900 \mathrm{~nm}\left(n_{900}\right)$, and calculated voids of MOF optical thin films.

\begin{tabular}{cccc}
\hline Samples & $n_{\text {ave }}$ & $\boldsymbol{n}_{\mathbf{9 0 0}}$ & $\boldsymbol{V}_{\text {void }}(\mathbf{\%})$ \\
\hline OTF-SP & $1.208 \pm 0.024$ & 1.2022 & 25.19 \\
OTF-DP-1 & $1.110 \pm 0.016$ & 1.1095 & 32.11 \\
OTF-DP-3 & $1.178 \pm 0.012$ & 1.1616 & 27.35 \\
OTF-DP-5 & $1.118 \pm 0.015$ & 1.1182 & 31.51 \\
OTF-SA-1 & $1.233 \pm 0.009$ & 1.2308 & 23.32 \\
OTF-SA-2 & $1.273 \pm 0.015$ & 1.2731 & 20.25 \\
OTF-SA-3 & $1.188 \pm 0.012$ & 1.1760 & 26.64 \\
OTF-LBL & $1.512 \pm 0.053$ & 1.4955 & 0 \\
\hline
\end{tabular}

\section{Conclusions}

In summary, the UiO-66-based thin films have been successfully prepared using five different methods. The OTF-SP film has a uniform color, greater reflectivity, flat microstructure, and minimal roughness. The quality of the OTF-DP film is related to the number of depositions. When the deposition times are few, the surface coverage is low, and when increasing the times of deposition, a more homogenous film can be obtained. The OTF-SA film has a uniform color, and the number of MOF layers is in direct proportion to the times of assembly, while the roughness decreases as the number of assembly increases, thanks to the interleaved filling of following nanocrystals. All the above three methods based on solution deposition of MOF nanoparticles have made a thin film with a lower refractive index (even < 1.22) and have the potential for application in antireflection films and other devices. The surface of the OTF-DG film is dark in color and has the highest roughness, which does not meet the requirements for use of optical films. The OTF-LBL has the brightest color, a flowing reflection spectrum curve (small scattering), dense and smooth film surface, low surface roughness, maximum effective refractive index, but small thickness, and a growth efficiency of about $3.4 \mathrm{~nm}$ per growth cycle.

Supplementary Materials: The following are available online at http:/ /www.mdpi.com/2079-4991/8/9/676/s1, experimental details, characterization of UiO-66 and Zr-precursor, reflection spectra, SEM images and generated and fitted curves of ellipsometry.

Author Contributions: Conceptualization, C.-a.T.; Methodology, C.-a.T. and Y.H.; Validation, Y.H., R.C. and J.W.; Formal Analysis, C.-a.T. and Y.H.; Investigation, Y.H. and R.C.; Resources, L.S.; Data Curation, Y.H., R.C. and C.-a.T.; Writing-Original Draft Preparation, C.-a.T.; Writing-Review \& Editing, L.S. and J.W.; Visualization, C.-a.T.; Supervision, C.-a.T. and L.S.; Project Administration, J.W.; Funding Acquisition, C.-a.T. 
Funding: This research was funded by the National Natural Science Foundation of China (21573285), Natural Science Foundation of Hunan Province (2018JJ3597) and research project of National University of Defense Technology (ZK16-03-51). The APC was funded by research project of National University of Defense Technology (ZK16-03-51).

Acknowledgments: Thanks are also given to Tianliang Qu for the help with the ellipsometry studies.

Conflicts of Interest: The authors declare no conflict of interest.

\section{References}

1. Sindoro, M.; Yanai, N.; Jee, A.-Y.; Granick, S. Colloidal-sized metal-organic frameworks: Synthesis and applications. Acc. Chem. Res. 2013, 47, 459-469. [CrossRef] [PubMed]

2. Bai, Y.; Dou, Y.; Xie, L.-H.; Rutledge, W.; Li, J.-R.; Zhou, H.-C. Zr-based metal-organic frameworks: Design, synthesis, structure, and applications. Chem. Soc. Rev. 2016, 45, 2327-2367. [CrossRef] [PubMed]

3. Murray, L.J.; Dincă, M.; Long, J.R. Hydrogen storage in metal-organic frameworks. Chem. Soc. Rev. 2009, 38, 1294-1314. [CrossRef] [PubMed]

4. Lee, J.; Farha, O.K.; Roberts, J.; Scheidt, K.A.; Nguyen, S.T.; Hupp, J.T. Metal-organic framework materials as catalysts. Chem. Soc. Rev. 2009, 38, 1450-1459. [CrossRef] [PubMed]

5. Wu, S.; Zhu, Y.; Huo, Y.; Luo, Y.; Zhang, L.; Wan, Y.; Nan, B.; Cao, L.; Wang, Z.; Li, M. Bimetallic organic frameworks derived $\mathrm{CuNi}$ /carbon nanocomposites as efficient electrocatalysts for oxygen reduction reaction. Sci. China Mater. 2017, 60, 654-663. [CrossRef]

6. Horcajada, P.; Chalati, T.; Serre, C.; Gillet, B.; Sebrie, C.; Baati, T.; Eubank, J.F.; Heurtaux, D.; Clayette, P.; Kreuz, C. Porous metal-organic-framework nanoscale carriers as a potential platform for drug delivery and imaging. Nat. Mater. 2010, 9, 172. [CrossRef] [PubMed]

7. Kreno, L.E.; Leong, K.; Farha, O.K.; Allendorf, M.; Van Duyne, R.P.; Hupp, J.T. Metal-organic framework materials as chemical sensors. Chem. Rev. 2011, 112, 1105-1125. [CrossRef] [PubMed]

8. Lu, G.; Hupp, J.T. Metal-organic frameworks as sensors: A ZIF-8 based Fabry-Pérot device as a selective sensor for chemical vapors and gases. J. Am. Chem. Soc. 2010, 132, 7832-7833. [CrossRef] [PubMed]

9. Cui, C.; Liu, Y.; Xu, H.; Li, S.; Zhang, W.; Cui, P.; Huo, F. Self-assembled metal-organic frameworks crystals for chemical vapor sensing. Small 2014, 10, 3672-3676. [CrossRef] [PubMed]

10. Hu, Z.; Tao, C.; Liu, H.; Zou, X.; Zhu, H.; Wang, J. Fabrication of an $\mathrm{NH}_{2}-\mathrm{MIL}-88 \mathrm{~B}$ photonic film for naked-eye sensing of organic vapors. J. Mater. Chem. A 2014, 2, 14222-14227. [CrossRef]

11. Serre, C.; Mellot-Draznieks, C.; Surblé, S.; Audebrand, N.; Filinchuk, Y.; Férey, G. Role of solvent-host interactions that lead to very large swelling of hybrid frameworks. Science 2007, 315, 1828-1831. [CrossRef] [PubMed]

12. Cavka, J.H.; Jakobsen, S.; Olsbye, U.; Guillou, N.; Lamberti, C.; Bordiga, S.; Lillerud, K.P. A new zirconium inorganic building brick forming metal organic frameworks with exceptional stability. J. Am. Chem. Soc. 2008, 130, 13850-13851. [CrossRef] [PubMed]

13. Park, K.S.; Ni, Z.; Côté, A.P.; Choi, J.Y.; Huang, R.; Uribe-Romo, F.J.; Chae, H.K.; O’Keeffe, M.; Yaghi, O.M. Exceptional chemical and thermal stability of zeolitic imidazolate frameworks. Proc. Nat. Acad. Sci. USA 2006, 103, 10186-10191. [CrossRef] [PubMed]

14. Wen, X.; Xiong, Q. A large scale perfect absorber and optical switch based on phase change material $\left(\mathrm{Ge}_{2} \mathrm{Sb}_{2} \mathrm{Te}_{5}\right)$ thin film. Sci. China Mater. 2016, 59, 1-8. [CrossRef]

15. Epstein, L.I. The design of optical filters. J. Opt. Soc. Am. 1952, 42, 806-808. [CrossRef]

16. Bétard, A.; Fischer, R.A. Metal-organic framework thin films: From fundamentals to applications. Chem. Rev. 2012, 112, 1055-1083. [CrossRef] [PubMed]

17. Zacher, D.; Shekhah, O.; Wöll, C.; Fischer, R.A. Thin films of metal-organic frameworks. Chem. Soc. Rev. 2009, 38, 1418-1429. [CrossRef] [PubMed]

18. Horcajada, P.; Serre, C.; Grosso, D.; Boissiere, C.; Perruchas, S.; Sanchez, C.; Férey, G. Colloidal route for preparing optical thin films of nanoporous metal-organic frameworks. Adv. Mater. 2009, 21, 1931-1935. [CrossRef]

19. Demessence, A.; Horcajada, P.; Serre, C.; Boissière, C.; Grosso, D.; Sanchez, C.; Férey, G. Elaboration and properties of hierarchically structured optical thin films of MIL-101 (Cr). Chem. Commun. 2009, 46, 7149-7151. [CrossRef] [PubMed] 
20. García Márquez, A.; Demessence, A.; Platero-Prats, A.E.; Heurtaux, D.; Horcajada, P.; Serre, C.; Chang, J.S.; Férey, G.; de la Peña-O'Shea, V.; Boissière, C. Green microwave synthesis of MIL-100 (Al, Cr, Fe) nanoparticles for thin-film elaboration. Eur. J. Inorg. Chem. 2012, 2012, 5165-5174. [CrossRef]

21. Redel, E.; Wang, Z.; Walheim, S.; Liu, J.; Gliemann, H.; Wöll, C. On the dielectric and optical properties of surface-anchored metal-organic frameworks: A study on epitaxially grown thin films. Appl. Phys. Lett. 2013, 103, 091903. [CrossRef]

22. Yin, W.; Tao, C.; Zou, X.; Wang, F.; Qu, T.; Wang, J. The tuning of optical properties of nanoscale mofs-based thin film through post-modification. Nanomaterials 2017, 7, 242. [CrossRef] [PubMed]

23. Yin, W.; Tao, C.; Wang, F.; Huang, J.; Qu, T.; Wang, J. Tuning optical properties of mof-based thin films by changing the ligands of MOFs. Sci. China Mater. 2018, 61, 391-400. [CrossRef]

24. Ranft, A.; Betzler, S.B.; Haase, F.; Lotsch, B.V. Additive-mediated size control of MOF nanoparticles. CrystEngComm 2013, 15, 9296-9300. [CrossRef]

25. Hu, Z.; Tao, C.; Wang, F.; Zou, X.; Wang, J. Flexible metal-organic framework-based one-dimensional photonic crystals. J. Mater. Chem. C 2015, 3, 211-216. [CrossRef]

26. Kandiah, M.; Nilsen, M.H.; Usseglio, S.; Jakobsen, S.; Olsbye, U.; Tilset, M.; Larabi, C.; Quadrelli, E.A.; Bonino, F.; Lillerud, K.P. Synthesis and stability of tagged UiO-66 Zr-MOFs. Chem. Mater. 2010, 22, 6632-6640. [CrossRef]

27. Choi, K.M.; Jeong, H.M.; Park, J.H.; Zhang, Y.-B.; Kang, J.K.; Yaghi, O.M. Supercapacitors of nanocrystalline metal-organic frameworks. ACS Nano 2014, 8, 7451-7457. [CrossRef] [PubMed]

28. Kickelbick, G.; Schubert, U. Oxozirconium methacrylate clusters: $\mathrm{Zr}_{6}(\mathrm{OH})_{4} \mathrm{O}_{4}(\mathrm{OMC})_{12}$ and $\mathrm{Zr}_{4} \mathrm{O}_{2}(\mathrm{OMC})_{12}$ (OMC = methacrylate). Chem. Ber. 1997, 130, 473-478. [CrossRef]

29. Užarević, K.; Wang, T.C.; Moon, S.-Y.; Fidelli, A.M.; Hupp, J.T.; Farha, O.K.; Friščić, T. Mechanochemical and solvent-free assembly of zirconium-based metal-organic frameworks. Chem. Commun. 2016, 52, 2133-2136. [CrossRef] [PubMed]

30. Schneider, C.A.; Rasband, W.S.; Eliceiri, K.W. NIH Image to ImageJ: 25 years of image analysis. Nat. Methods 2012, 9, 671-675. [CrossRef] [PubMed]

31. Sihvola, A. Mixing rules with complex dielectric coefficients. Subsurf. Sens. Technol. Appl. 2000, 1, $393-415$. [CrossRef]

(C) 2018 by the authors. Licensee MDPI, Basel, Switzerland. This article is an open access article distributed under the terms and conditions of the Creative Commons Attribution (CC BY) license (http:/ / creativecommons.org/licenses/by/4.0/). 